\title{
CAUSAS E SINTOMAS DA HALITOSE: ESTUDO DO CONHECIMENTO ENTRE PACIENTES DO CURSO DE ODONTOLOGIA
}

\author{
CAUSES AND SYMPTOMS OF HALITOSIS: A STUDY OF KNOWLEDGE \\ AMONG PATIENTS OF THE DENTISTRY COURSE
}

\author{
Ana Claudia de Abreu* \\ Patricia Aleixo dos Santos Domingos** \\ Andrea Abi Rached Dantas***
}

\begin{abstract}
RESUMO
Introdução: O estudo avalia o conhecimento sobre causas e sintomas da halitose de pacientes da Clínica de Odontologia do Curso de Graduação do Centro Universitário de Araraquara - UNIARA, bem como analisa a eficiência de folheto educativo na mudança de comportamento quanto à prevenção do mau hálito. Métodos: Para isso, um questionário pré-codificado, composto por questões sobre o tema foi aplicado em 2 momentos: antes e após 30 dias da realização do experimento. A amostra foi composta por 30 pacientes, divididos em 2 grupos: GA - controle (respondeu ao questionário); GB - respondeu ao questionário e recebeu o folheto para leitura e novamente respondeu ao questionário, passados 30 dias da aplicação do folheto. Os grupos foram comparados por meio da coleta dos dados e análise descritiva da distribuição de frequências. Resultados: Os resultados mostraram que, de maneira geral, o conhecimento sobre halitose se mostrou controverso em alguns aspectos, principalmente, em relação às causas e formas de prevenção; não foi observada melhora no conhecimento sobre halitose para o grupo que recebeu o folheto. Conclusão: Tanto os profissionais quanto a população devem ser mais bem orientados em relação aos fatores fisiológicos e patológicos da halitose para atuarem na prevenção de seus efeitos individuais e sociais.
\end{abstract}

DESCRITORES: Halitose, prevenção e controle • Odontologia preventiva

\section{ABSTRACT}

Introduction: This study aims to evaluate the knowledge about the causes and symptoms of halitosis of patients in the clinic of Dentistry of the University Center of Araraquara - UNIARA and analyze the effectiveness of an educational booklet on behavior change in relation to preventing bad breath. Methods: For that, a pre-coded questionnaire, was applied in two phases: before and after 30 days of the study. The sample consisted of 30 patients divided into two groups: GA - control group (only answered the questionnaire); GB - answers questionnaire and received the booklet to read and answer the questionnaire again, after 30 days of booklet application. The groups were compared by means of data collection and descriptive analysis using distributions of frequency. Results: The results showed that, in general, knowledge about halitosis by the studied population was controversial in some respects, especially with regard to the causes and prevention methods; no improvement was observed about halitosis for the group who received the booklet compared with the control group. Conclusion: It may be concluded that professionals and the population must be better focused on the physiological and pathological halitosis, so that they may act to prevent individual and social effects.

DESCRIPTORS: Halitosis, prevention e control • Preventive dentistry

\footnotetext{
* Cirurgiã-Dentista formada no Centro Universitário de Araraquara, UNIARA. Email: acbreu@hotmail.com

** Professora Doutora Responsável pela disciplina de Odontologia em Saúde Coletiva do Curso de Odontologia do Centro Universitário de Araraquara, UNIARA. Email: patyaleixo01@yahoo.com.br

*** Professora Doutora Responsável pela disciplina de Periodontia do Curso de Odontologia do Centro Universitário de Araraquara, UNIARA. Email: aarached@yahoo.com.br
} 


\section{N T RO DUÇÃO}

A preocupação com o mau hálito não é um problema que surgiu com a sociedade moderna. No período antes de Cristo, os antigos já apresentavam indícios de incômodo com o mau hálito. Titus Martius Plautus (254-184 a.C.) classificou o fedor emanado da boca entre as muitas razões de infidelidade conjugal. Na Ucrânia, era recomendado que a pessoa ficasse em pé de frente para a lua, recolhesse a terra debaixo do calcanhar e esfregar os dentes com ela. Na Europa central, as folhas de alecrim eram mascadas, após as refeições, para amenizar o odor desagradável de alguns alimentos (Kolbe e Britto ${ }^{1}, 2004$ ). Outras sugestões encontradas na literatura são os bochechos com a própria urina dos pacientes para solucionar o problema (Fernandes et al. ${ }^{2}$, 2007).

Atualmente, a Odontologia está voltada, principalmente, para a prevenção e diagnóstico das doenças bucais, como a cárie dental, as doenças periodontais e os problemas relacionados às más oclusões, dispondo ainda de grande preocupação com a estética do sorriso. Não menos importante, o mau hálito tem se apresentado com papel de destaque na Odontologia como um problema de saúde pública, de difícil diagnóstico devido a suas causas multifatoriais. A halitose causa um transtorno na vida social, afetiva e profissional do indivíduo, refletindo na sua saúde emocional (Calil et al. ${ }^{3}, 2006$, Gorender ${ }^{4}$, 2004).

O termo halitose deriva do latim, em que halitos significa "ar expirado" e osis uma "alteração patológica" o que pode, simplesmente ser descrito como "hálito desagradável" (Hine $\left.{ }^{5}, 1957\right)$. É uma alteração que pode ser de origem local ou sistêmica, caracterizada pelos odores desagradáveis emanados. Na maioria dos casos, estes são resultados do metabolismo da microbiota bucal (Moreno et al. ${ }^{6}$, 2005).

Estudos mostraram que a degradação de aminoácidos, principalmente dos que contêm enxofre, advindos da dieta em consequência da metabolização das bactérias presentes na boca, na maioria as gram-negativas anaeróbicas de vários substratos sulfurados, produzem os Compostos Sulfurados Voláteis (CSV). Esses compostos são, principalmente, formados pela junção de sulfeto de hidrogênio (H2S), metil mercaptana $(\mathrm{CH} 3 \mathrm{SH})$ e o dimetil sulfeto $(\mathrm{CH} 3 \mathrm{SCH} 3)$, sendo estes em maior quantidade. Estão presentes, ainda, em menor quantidade, ácidos butínico, propiônico, valérico e cadaverina, que são os principais responsáveis pelo cheiro desagradável emitido (Leite e Montene$\left.\mathrm{gro}^{7}, 2006\right)$. Os principais microrganismos produtores do CSV são a bacteroide forsythus, a treponema denticola e Porphyromonas (Calil et al. ${ }^{3}$, 2006).

A placa dental e a saburra lingual são os maiores responsáveis pelo odor fétido, e os principais locais onde as bactérias produtoras de CSV habitam (Derceli et al. $\left.{ }^{8}, 2005\right)$. Consequentemente, a alteração dos maus hábitos de higiene bucal, ou a falta desta, diminuem os nichos para as bactérias que produzem CSVs.

A saburra lingual se caracteriza por uma camada esbranquiçada que se adere ao dorso da língua, em maior proporção no terço posterior, composta, principalmente, por restos alimentares, células epiteliais mortas, bactérias e enzimas ativas que participam do processo de digestão, dentre outras coisas. Essa camada esbranquiçada ajuda a diminuir o paladar, em decorrência das papilas gustativas estarem obstruídas (Derceli et al. $\left.{ }^{8}, 2005\right)$. Tal fato ocasiona o aumento de sal e açúcar na dieta, o que agrava e aumenta os casos de hipertensão arterial e da diabete mellitus (Montenegro et al. ${ }^{9}, 2006$ ).

Dentre as inúmeras causas que podem desenvolver a halitose, em sua maioria relacionadas com a produção dos CSV, existem duas categorias: causas locais, relacionadas à cavidade bucal e causas gerais, de origem sistêmica (Fernandes et al. $\left.{ }^{2}, 2007\right)$.

Relacionados às causas de origem local, podem-se citar os processos cariosos e suas sequelas, placa bacteriana, gengivite, língua fissurada, peças protéticas mal adaptadas, alterações na composição da saliva e as fontes de halitose mais relevantes, que são a língua saburrosa e as periodontopatias (Albuquerque et al. ${ }^{10}$, 2004).

As causas ainda podem ser de origem
ABREU AC

DOMINGOS PAS

DANTAS AAR

CAUSAS E

SINTOMAS DA

HALITOSE:

ESTUDO DO

CONHECIMENTO

entre pacientes

DO CURSO DE

ODONTOLOGIA
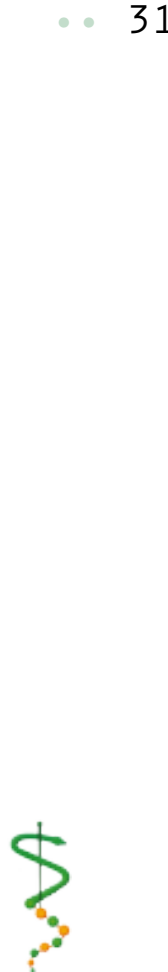

REVISTA DE ODONTOLOGIA DA UN I VERS I DADE Cidade de São PAULO

2011; 23(1): 30 41, JAN-ABR 
I SSN 1983-5183

ABREU AC DOMINGOS PAS

DANTAS AAR

CAUSAS E

SINTOMAS DA

HALITOSE:

ESTUDO DO

CONHECIMENTO

ENTRE PACIENTES

DO CURSO DE

ODONTOLOGIA



REVISTA DE ODONTOLOGIA DA UNIVERSIDADE CIDADE DE SÃO

PAULO

$2011 ; 23(1): 30-$

41, JAN-ABR sistêmica, como as respiratórias (sinusite, amidalite, rinites, bronquites e abscessos) e digestivas (neoplasias, erupção gástrica, úlcera duodenal e retenção alimentar) ou de alterações metabólicas como diabetes, alterações hormonais e causas de xerostomias (Fernandes et al. ${ }^{2}, 2007$ ).

A saliva é uma excelente aliada à limpeza mecânica da cavidade bucal: isso, a diminuição do fluxo salivar influencia consideravelmente. Estudos mostraram que, durante o sono, o fluxo salivar é mais baixo e a produção dos CSV aumenta, devido ao acúmulo de células epiteliais e restos alimentares (Kolbe e Britto ${ }^{1}$, 2004).

A halitose pode se agravar, dependendo do horário, como ao levantar de manhã, pois existe a presença da halitose matinal, devido à diminuição do fluxo salivar, dependendo da idade do paciente, sendo que o paciente jovem hálito mais adocicado e paciente mais velho apresenta hálito forte e pesado. Pode ocorrer também em mulheres grávidas, em período de amamentação e durante o ciclo menstrual, que são períodos de intensa alteração hormonal.

Os cirurgiões-dentistas não devem deixar de prestar atenção no fator estresse e ansiedade. Estudos realizados com ratos mostraram que o estresse provocado nesses animais induzem a grande aumento nas concentrações de CSV na cavidade bucal (Koshimune et al. ${ }^{11}, 2003$ ).

A halitose se transforma em transtorno na vida das pessoas, visto que os portadores sentem dificuldade em identificar, devido à capacidade que nosso nariz tem de se acostumar com o cheiro em pouco tempo, sendo percebido apenas no primeiro contato. Muitas vezes, os portadores da halitose desconhecem possuí-la, causando interferência na sua vida social, afetiva e profissional. Por ser uma doença multifatorial, o tratamento da halitose é dificultado, sendo preciso, primeiramente, identificar a possível causa, recomendando-se para todos os casos uma boa higienização oral, incluindo a limpeza mecânica do dorso da língua que, infelizmente, é um costume pouco exercido.

Um estudo comparando a limpeza da língua, no qual diversos instrumentos foram testados como gaze, escova dental e limpador de língua convencional, mostrou que o raspador lingual apresenta melhor rendimento, pois elimina maior quantidade de saburra lingual, devido a sua anatomia desenvolvida para melhor adaptação da língua, sendo até mais confortável para o paciente, diminuindo a incidência de ânsia de vômito, seguido da escova dental e da limpeza digital com uma gaze, que se mostrou ser o método menos eficiente (Cerri e Silva ${ }^{12}$, 2002). Outro trabalho publicado na literatura comparou quatro marcas comerciais, disponíveis no mercado brasileiro: Periogard $\AA$, Listerine $\AA$, Cepacol ${ }^{\circledR}$ e $\operatorname{Plax} \circledast$. Os pesquisadores concluíram que, apesar de todas serem efica-

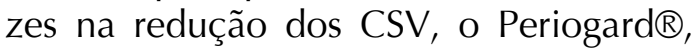
composto de clorexidina $0,12 \%$, continua sendo a melhor opção (Carvalho et al. ${ }^{13}$, 2003).

Dessa forma, o presente estudo tem, prioridade, investigar os conhecimentos da população de pacientes atendidos na Clínica de Atendimento do Curso de Graduação em Odontologia do Centro Universitário de Araraquara - UNIARA, sobre a halitose.

Diante disso, o presente estudo tem o objetivo de avaliar o conhecimento sobre as causas e sintomas da halitose de pacientes frequentadores da Clínica de Odontologia do Curso de Graduação do Centro Universitário de Araraquara UNIARA, bem como analisar a eficiência de um folheto educativo na mudança de comportamento em relação à prevenção do mau hálito.

\section{MÉTODOS}

A realização deste estudo esteve vinculada à aprovação do Comitê de Ética em Pesquisa do Centro Universitário de Araraquara - UNIARA, sob protocolo $n^{\circ}$ 909/09, estando a participação dos pacientes vinculada ao correto preenchimento e assinatura do Termo de Consentimento Pré-Informado.

O planejamento amostral foi não probabilístico, sendo a amostra selecionada por interesse e composta por 30 pacientes adultos, com faixa etária entre 30 e 50 anos, de ambos os sexos, frequentadores regulares da Clínica de Atendimento do Curso de Graduação em Odontologia 
Tabela 1 - Distribuição da frequência absoluta (n) e relativa (\%) dos participantes, segundo o grupo avaliado de acordo com diferentes aspectos pessoais. Araraquara, 2009.

\begin{tabular}{lcccc} 
Aspectos Pessoais & \multicolumn{2}{c}{ GA } & N & $\%$ \\
& Sexo & & & \\
Masculino & 6 & 40,0 & 7 & 46,6 \\
Feminino & 9 & 60,0 & 8 & 53,4 \\
& Grupo de Idade & & & \\
$30-34$ anos & 4 & 26,6 & 1 & 06,6 \\
$35-39$ anos & 3 & 20,0 & 2 & 13,3 \\
$40-50$ anos & 8 & 53,4 & 12 & 80,1 \\
& Escolaridade & & & \\
Ensino Fundamental incompleto & 3 & 20,0 & 4 & 26,6 \\
Ensino Fundamental completo & 3 & 20,0 & 3 & 20,0 \\
Ensino Médio & 6 & 40,0 & 8 & 53,4 \\
Ensino Superior & 3 & 20,0 & 0 & 00,0 \\
TOTAL DE PARTICIPANTES & 15 & 100,0 & 15 & 100,0 \\
\hline
\end{tabular}

do Centro Universitário de Araraquara UNIARA. Os pacientes foram selecionados pela faixa etária descrita acima.

$\mathrm{O}$ instrumento de medida empregado foi um questionário, contendo questões objetivas, as quais possuíam somente uma resposta correta.

É importante salientar que o instrumento utilizado foi previamente validado e apresentou boa concordância ( $\mathrm{K}=0.92)$.

O questionário foi aplicado na sala de espera da Clínica Odontológica do Centro Universitário de Araraquara - UNIARA, onde os participantes da pesquisa responderam individualmente.

Após a validação do instrumento de medida, a pesquisa foi realizada da seguinte forma:

- Inicialmente, todos os participantes selecionados para a pesquisa ( $\mathrm{n}$ $=30$ ) receberam um questionário composto por perguntas objetivas sobre os temas citados, o qual foi respondido sem nenhuma orientação, para não haver interferência do pesquisador e entregue com a devida identificação.

- Em seguida, os participantes foram divididos em dois grupos:

Grupo A (GA) - 15 pacientes, pertencentes ao grupo-controle da pesquisa. Responderam ao ques- tionário aplicado inicialmente e após duas semanas.

Grupo B (GB) - 15 pacientes responderam ao mesmo questionário, no momento inicial da pesquisa, e cada um deles recebeu o folheto autoexplicativo sobre as causas da halitose e instruções orais sobre sua prevenção. Alguns leram imediatamente e outros levaram para casa. Passados trinta (30) dias, o formulário foi reaplicado.

\section{RESULTADOS}

Os dados obtidos com as respostas fornecidas pelos participantes da pesquisa após a aplicação do questionário nos grupos A e B, foram categorizados e apresentados pela distribuição de frequências, com o auxílio do programa Excel, sendo demonstrados nas tabelas, a seguir:

A Tabela 1 mostra a distribuição dos participantes avaliados, de acordo com os dados relativos aos aspectos pessoais: sexo, grupo de idade e escolaridade. Com relação ao sexo, verificou-se a predominância do sexo feminino (60,0\% e 53,4\%) sobre o masculino $(40,0 \%$ e $46,6 \%)$ em ambos os grupos avaliados.

Observa-se que a idade dos participantes variou entre 30 a 50 anos, sendo os maiores índices encontrados na faixa etá-
ABREU AC

DOMINGOS PAS

DANTAS AAR

CAUSAS E SINTOMAS DA HALITOSE:

ESTUDO DO

CONHECIMENTO entre pacientes DO CURSO DE ODONTOLOGIA

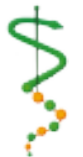

REVISTA DE ODONTOLOGIA DA UN I VERS I DADE CIDADE DE São PAULO

$2011 ; 23(1): 30-$ 41 , JAN-ABR 
ABREU AC DOMINGOS PAS

DANTAS AAR

CAUSAS E

SINTOMAS DA

HALITOSE:

ESTUDO DO

CONHECIMENTO

ENTRE PACIENTES

DO CURSO DE

ODONTOLOGIA

Tabela 2 - Distribuição de frequência absoluta (n) e relativa (\%) dos participantes, segundo o grupo, das respostas fornecidas quanto ao comportamento de saúde geral e hábitos alimentares. Araraquara, 2009.

\begin{tabular}{ccccc}
\multicolumn{2}{c}{ Questões/Respostas } & \multicolumn{2}{c}{ GA } & \multicolumn{2}{c}{ ABtes } & Depois & Antes & Depois \\
Não & Come gordura ou comida temperada? \\
Sim & $4(26,6)$ & $9(60,0)$ & $7(46,6)$ & $7(46,6)$ \\
& $11(73,4)$ & $6(40,0)$ & $8(53,4)$ & $8(53,4)$
\end{tabular}

Fica muito tempo sem comer ou costuma não realizar refeições?

$\begin{array}{lllll}\text { Não } & 8(53,4) & 8(53,4) & 6(40,0) & 8(53,4) \\ \text { Sim } & 7(46,6) & 7(46,6) & 9(60,0) & 7(46,6)\end{array}$

Consome bebida alcoólica com frequência?

1 vez por semana

2 vezes por semana

Diariamente

Não respondeu

Sim

TOTAL DE PARTICIPANTES

$\begin{array}{llll}4(26,6) & 4(26,6) & 4(26,6) & 5(33,3) \\ 4(26,6) & 2(13,3) & 2(13,3) & 0(00,0) \\ 7(46,6) & 1(06,6) & 0(00,0) & 0(00,0) \\ 0(00,0) & 8(53,4) & 9(60,0) & 10(66,7)\end{array}$

Fuma?

$\begin{array}{cccc}13(86,7) & 13(86,7) & 14(93,4) & 14(93,4) \\ 2(13,3) & 2(13,3) & 1(06,6) & 1(06,6)\end{array}$

15

100,0

100,0

Tabela 3 - Distribuição de frequência absoluta (n) e relativa (\%) dos participantes, segundo o grupo, das respostas fornecidas quanto ao comportamento de saúde geral. Araraquara, 2009.

\begin{tabular}{lcccc} 
Questões/Respostas & \multicolumn{2}{c}{ GA } \\
Tem diabetes? & Antes & Depois & Antes & depois \\
Não & $12(80,0)$ & $12(80,0)$ & $13(86,7)$ & $13(86,7)$ \\
Sim & $2(13,3)$ & $2(13,3)$ & $2(13,3)$ & $2(13,3)$ \\
Não sei & $1(06,6)$ & $1(06,6)$ & $0(00,0)$ & $0(00,0)$ \\
Respira pela boca? & & & \\
Não & $10(66,6)$ & $9(60,0)$ & $7(46,6)$ & $6(40,0)$ \\
Sim & $3(20,0)$ & $5(33,3)$ & $5(33,3)$ & $9(60,0)$ \\
Não sei & $2(13,3)$ & $1(06,6))$ & $3(20,0)$ & $0(00,0)$ \\
Ronca durante o sono? & & & & \\
Não & $9(60,0)$ & $9(60,0)$ & $8(53,4)$ & $7(46,6)$ \\
Sim & $3(20,0)$ & $3(20,0)$ & $3(20,0)$ & $3(20,0)$ \\
Não sei & $3(20,0)$ & $3(20,0)$ & $4(26,6)$ & $5(33,3)$ \\
TOTAL DE PARTICIPANTES & 15 & 100,0 & 15 & 100,0 \\
\hline
\end{tabular}

ria de 40 a 50 anos, tanto para o Grupo A $(53,4 \%)$ como para o Grupo B (80,1\%).

No que diz respeito ao grau de escolaridade, notou-se que 20,0\% do Grupo A responderam possuir ensino superior, sendo predominante a porcentagem de pessoas com ensino médio $(40,0 \%)$. No Grupo B, observou-se que 53,4\% haviam cursado ensino médio e nenhum dos participantes havia cursado o ensino superior.
Ao serem questionados sobre seus hábitos alimentares, a Tabela 2 mostra que, no primeiro momento de avaliação, 11 (73,4\%) indivíduos do Grupo A responderam que consomem alimentos gordurosos e temperados, enquanto que no Grupo B $8(53,4 \%)$ pessoas fizeram essa afirmação. No momento posterior, o Grupo A mostrou diminuição nesse consumo e o Grupo B se manteve inalterado $(40,0 \%$ e 
$53,4 \%$, respectivamente).

Em relação ao hábito de realizar poucas refeições ao dia (muito tempo sem comer ou pular refeições), notou-se, no primeiro momento, que houve semelhança na porcentagem de respostas positivas $(53,4 \%)$ e negativas $(46,6 \%)$ para esse aspecto no Grupo A e no Grupo B, sendo que as respostas positivas foram mais frequentes $(60,0 \%)$. Já em um segundo momento, tanto o Grupo A como o Grupo B mantiveram o comportamento inicial.

No que se refere ao consumo de bebidas alcoólicas, observou-se, no momento inicial, que grande parcela $(46,6 \%)$ do Grupo A assumiu tal hábito diariamente, enquanto que, no Grupo B, 60,0\% dos entrevistados não responderam à pergunta e $26,6 \%$ responderam consumi-las $1 \mathrm{vez}$ por semana. Na segunda avaliação, houve diminuição da porcentagem de indivíduos $(06,6 \%)$ do Grupo A para o consumo diário e o Grupo B se manteve praticamente sem alteração.

Outro hábito avaliado foi o consumo de cigarro. Quando questionada sobre o fumo, notou-se que a maioria da população estudada não era fumante $(86,7 \%$ e $93,4 \%$ ) para os dois grupos (GA e GB, respectivamente).

A Tabela 3 apresenta os resultados encontrados para as questões referentes à saúde geral e alterações sistêmicas. Os participantes foram questionados a respeito do diagnóstico de diabetes e, nas duas vezes em que foram entrevistados, a maioria do Grupo A e do B afirmou não apresentar este problema de saúde (80,0\% e $86,7 \%$, respectivamente).

No que diz respeito à respiração bucal, verificou-se que no Grupo $A$ as respostas foram negativas para a maioria dos entrevistados $(60,0 \%$ e $66,6 \%$, nos momentos antes e depois, respectivamente). No Grupo B, houve maior distribuição das respostas entre "sim", "não" e "não sei" (46,6\%, 33,3\% e 20,0\%, respectivamente) no início da pesquisa, porém, após serem apresentados ao folheto explicativo, houve alteração na porcentagem das respostas, observando-se que $40,0 \%$ deles disseram não respirar pela boca e 60,0\% confirmaram esse hábito.

Ainda em relação ao comportamento de saúde geral, o questionário abordava o assunto ronquidão. Nos resultados encontrados, verificou-se para ambos os momentos da pesquisa que, de maneira geral, significativa parcela dos participantes (20 a 33,3\%) não sabia relatar sobre terem notado se roncavam durante o sono e, por outro lado, a maioria respondeu não apresentar o problema ao dormir $(60,0$ e $53,4 \%)$.

$\mathrm{Na}$ Tabela 4, em que são abordadas questões relativas à saúde bucal, resultados semelhantes foram verificados na população estudada relativos à sensação de sabor desagradável na cavidade bucal, mesmo após a escovação.

Ao serem questionados sobre o sangramento gengival, a maioria dos integrantes do GA respondeu negativamente $(73,3 \%)$ antes e depois dos 30 dias de intervalo entre as avaliações, enquanto que no GB, maior parcela do grupo notava esse sintoma no momento inicial $(20,0 \%)$, havendo aumento das respostas positivas no momento final de avaliação (40,0\%).

No que se refere à prevenção da gengivite, por meio do uso do fio dental, os entrevistados foram indagados sobre a frequência de utilização. Os resultados encontrados mostraram que, na primeira aplicação do questionário a resposta mais comum para ambos os grupos foi do uso diário $(46,6 \%$ e $40,0 \%$, respectivamente), sendo que o uso por 2 ou mais vezes ao dia também foi respondido por outros $46,6 \%$ do GA. No segundo momento, as porcentagens de respostas para uso diário diminuíram e para uso 2 ou mais vezes ao dia aumentou, tanto no GA como no GB (53,4\% e 46,6\%, respectivamente).

Em relação à presença de "tártaro" ou cálculo dental, é importante salientar que muitos participantes da pesquisa não souberam responder à pergunta, por não terem certeza se apresentavam a placa mineralizada ou não (GA - 33,3\% e GB - 40,0\%). Todavia, após 30 dias, notou-se que mais pessoas afirmaram não possuir cálculo na cavidade bucal (GA - 46,6\% e GB - 66,6\%).

Para a pergunta que se referiu a presença de saburra no dorso da língua, obtevese resposta "não" para significativa parcela da população estudada, em ambos os
ABREU AC DOMINGOS PAS

DANTAS AAR

CAUSAS E SINTOMAS DA HALITOSE: ESTUDO DO CONHECIMENTO ENTRE PACIENTES DO CURSO DE ODONTOLOGIA
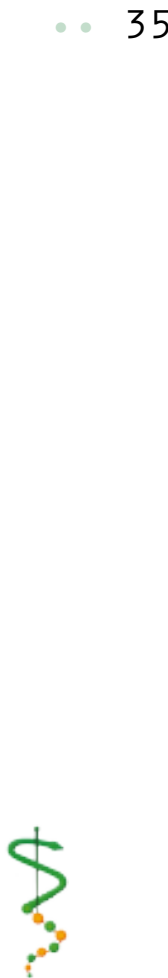

REVISTA DE ODONTOLOGIA DA UNIVERS I DADE Cidade de São PAULO

2011; 23(1): 30 41, JAN-ABR 
$A B R E U$ AC DOMINGOS PAS

DANTAS AAR

CAUSAS E

SINTOMAS DA

HALITOSE:

ESTUDO DO

CONHECIMENTO

ENTRE PACIENTES

DO CURSO DE

ODONTOLOGIA

Tabela 4 - Distribuição de frequência absoluta (n) e relativa (\%) dos participantes, segundo o grupo, das respostas fornecidas quanto aos hábitos de higiene bucal e conhecimento sobre a halitose. Araraquara, 2009.

\begin{tabular}{|c|c|c|c|c|}
\hline \multirow{2}{*}{ Questões/Respostas } & \multicolumn{2}{|c|}{ GA } & \multicolumn{2}{|c|}{ GB } \\
\hline & Antes & Depois & Antes & depois \\
\hline \multicolumn{5}{|c|}{ Sente gosto ruim na boca após escovação? } \\
\hline Não & $12(80,0)$ & $12(80,0)$ & $11(73,3)$ & $12(80,0$ \\
\hline Sim & $3(20,0)$ & $3(20,0)$ & $4(26,6)$ & $3(20,0)$ \\
\hline
\end{tabular}

Sua gengiva sangra?

Não

$11(73,3) \quad 11(73,3) \quad 6(40,0) \quad 7(46,6)$

Sim

$1(06,6)$

Às vezes

$3(20,0)$

$2(13,3)$

$3(20,0)$

$6(40,0)$

Com qual frequência usa o fio dental?

1 vez ao dia

$7(46,6) \quad 5(33,4) \quad 6(40,0) \quad 4(26,6)$

2 ou mais vezes ao dia

1 vez por semana

$7(46,6) \quad 8(53,4)$

$5(33,4)$

$7(46,6)$

Não usa

$0(00,0)$

$1(06,6)$

$2(13,3)$

$2(13,4)$

Tem tártaro?

Não

Sim

$1(06,6)$

$1(06,6)$

$2(13,3)$

$2(13,4)$

Não sei

$5(33,3)$

$7(46,6)$

$6(40,0)$

$10(66,6)$

Apresenta camada esbranquiçada sobre a língua?

Não

Sim

$5(33,3)$

$4(26,6)$

$3(20,0)$

$3(20,0)$

$4(26,6)$

$6(40,0)$

$2(13,3)$

Usa aparelho ortodôntico ou prótese?

Não

Sim

$10(66,6)$

$11(73,3)$

$11(73,3)$

$11(73,3)$

$5(33,3)$

$4(26,6)$

$4(26,6)$

$4(26,6)$

O que faz para prevenir o mau hálito?

Mascar chiclete

Tomar água

$13(86,7)$

$12(80,0)$

$7(46,6)$

$9(60,0)$

$2(13,3)$

$3(20,0)$

$8(53,4)$

$6(40,0)$

Higienização bucal

Você acredita que tem mau hálito?

Não

Sim

$2(13,3)$

$2(13,3)$

$2(13,3)$

$4(26,6)$

$2(13,3)$

$3(20,0)$

$11(73,3$

$9(60,0)$

$2(13,3)$

$0(00,0)$

$12(80,0)$

Não sei

$9(60,0)$

$9(60,0)$

$11(73,3)$

$12(80,0)$

TOTAL DE PARTICIPANTES

$2(13,3)$

$2(13,3)$

$7(46,6)$

$9(60,0)$

$4(26,6)$

$4(26,6)$

$3(20,0)$

$4(26,6)$

momentos de investigação (GA - 66,6$73,3 \%$ e GB - 73,3\%).

Foi observado também que relevante número de participantes deste trabalho relatou utilizar-se de algum dispositivo retentor de placa bacteriana, como aparelho ortodôntico ou prótese (aproximadamente $80,0 \%$ no GA e entre 46 e $60 \%$ no GB).

No que diz respeito às formas adotadas para a prevenção do mau hálito, as respostas encontradas foram: 13,3 a 20,0\%

se utilizavam de goma de mascar (chicletes); 13,3 a 26,6\% tomavam água para disfarçar o odor da cavidade bucal; e, de 60 a $80 \%$ dos entrevistados relataram empregar a higienização bucal adequada como medida preventiva.

Por fim, os indivíduos da pesquisa foram questionados a respeito de sua opinião sobre possuir ou não o mau hálito. Notou-se que muitas pessoas não sabiam relatar sobre si mesmas (GA - 26,6\% e GB 
- 33,3\%), porém, muitos se consideravam livres do problema $(60,0 \%$ de ambos os grupos após 30 dias de avaliação).

\section{I SCUSSÃO}

A halitose é considerada um problema de saúde pública por ser passível de ser prevenida, poder causar certo grau de morbidade e os meios de prevenção ainda não serem adequadamente utilizados.

Embora seja um assunto bastante discutido desde a antiguidade e já tendo sido apresentados várias alternativas para diminuição dos seus sintomas, como o consumo de alimentos ou substâncias (gengibre, hortelã, água, alecrim, entre outros) que mascarem o mau odor bucal, nota-se que a preocupação é maior em utilizar medidas paleativas do que as condutas adequadas de higienização e mudança de hábitos. Assim, o profissional ainda apresenta, nos dias atuais, dificuldade em conscientizar a população no combate desse fenômeno que ocorre em grande número dos pacientes (Faber ${ }^{14}, 2009$ ).

Para que se possa prevenir esse grande incômodo que afeta os pacientes, tornase necessário conhecer suas possíveis causas. Os principais fatores de susceptibilidade à halitose foram investigados no presente estudo e encontra-se na literatura o fator idade como sendo uma das causas do problema. Isso ocorre devido a variações fisiológicas conforme o envelhecimento dos indivíduos, assim como alterações hormonais, o que pode ser observado em mulheres durante o período menstrual ou na gravidez e amamentação. Nos idosos, uma característica bastante peculiar e que, muitas vezes, pode ser considerada a causa da halitose é a presença de sulcos e fissuras na língua, pois favorecem maior depósito saburroide e, por isso, a higiene desses pacientes deve ser muito mais cuidadosa e detalhada (Derceli et al. $\left.{ }^{8}, 2005\right)$.

No presente estudo, em que a maioria da população estudada era composta de mulheres entre 40 e 45 anos, não foi observada relação direta entre esses fatores relacionados com sexo e idade, uma vez que, ao serem indagados sobre acreditarem serem portadores do mau hálito, mais da metade dos entrevistados não se consideravam afetados pelo problema.
Outro aspecto discutido nas pesquisas está relacionado ao consumo de alimentos muito temperados ou gordurosos, além do cigarro e de bebidas alcoólicas. Autores como Faber ${ }^{14}$ (2009) consideram que a problemática do mau hálito é multifatorial, já que o envolvimento pode ser estabelecido a partir de dietas variadas (pastosas ou líquidas), hábitos (fumo, bebidas), problemas psicossociais, endócrino-metabólicos. Períodos de crises emocionais também podem acarretar mudanças no hálito, jejuns prolongados ou pela manhã (Fernandes et al. ${ }^{2}, 2007$ ).

Os resultados encontrados neste estudo mostraram que pequena parcela dos participantes relatou ser fumante e consumidora frequente de bebida alcoólica. Além disso, muitas pessoas apresentavam o hábito de não realizar refeições e se alimentar de comida gordurosa e/ou temperada. Isso mostra que, por um lado, o fato de não serem fumantes as fez acreditar que isso era um importante motivo para não apresentarem mau hálito; por outro lado, a alimentação poderia comprometer o odor emanado pela cavidade bucal. A literatura confirma que o uso de cigarro, charuto, caximbo, maconha, etc, acarreta no hálito odor semelhante ao fumo usado e, em alguns casos, o mau hálito é extremamente desagradável (Crispim e Sampaio ${ }^{15}$, 1999). No que diz respeito ao tipo de alimento consumido, no que se refere aos condimentos e seu intenso aroma, dentre as causas gerais, tem-se uma mistura de substâncias voláteis procedentes do intestino por absorção e eliminação pulmonar como cebola, alho, certas bebidas e ácidos gordurosos (Faber ${ }^{14}, 2009$ ).

As doenças sistêmicas também são importante fator desencadeador de halitose, embora as maiores causas sejam de origem bucal. De maneira geral, todas as doenças que proporcionam xerostomia nos pacientes, como diabetes e hipertensão, muitas vezes como efeito adverso do medicamento de controle da doença crônica, podem ser potencializadoras do mau hálito. Neste trabalho, notou-se que poucos indivíduos apresentavam diabetes, sendo este outro fator motivador das respostas negativas para presença de halitose.

A respiração bucal associada ao ronco
ABREU AC DOMINGOS PAS

DANTAS AAR

CAUSAS E SINTOMAS DA HALITOSE: ESTUDO DO CONHECIMENTO ENTRE PACIENTES DO CURSO DE odONTOLOGIA
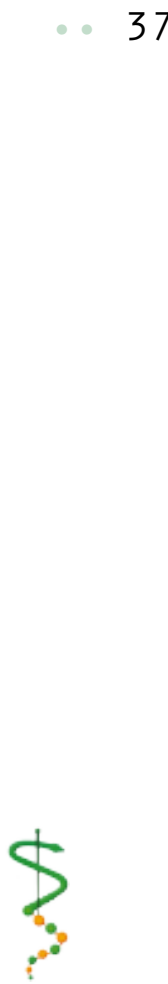

REVISTA DE ODONTOLOGIA DA UN I VERS I DADE Cidade de São PAULO

2011; 23(1): 30 41 , JAN-ABR 
ABREU AC DOMINGOS PAS

DANTAS AAR

CAUSAS E

SINTOMAS DA

HALITOSE:

ESTUDO DO

CONHECIMENTO

ENTRE PACIENTES

DO CURSO DE

ODONTOLOGIA

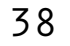

REVISTA DE

ODONTOLOGIA DA

UNI VERSIDADE

CIDADE DE SÃO

PAULO

2011; 23(1): $30-$

41 , JAN-ABR
ISSN 1983-5183

durante o sono também são considerados elementos que influenciam na diminuição do fluxo salivar e, por isso, podem estar diretamente relacionados com a halitose. Os participantes desta pesquisa relataram inicialmente, em sua maioria, não serem respiradores bucais, porém, no grupo em que o folheto explicativo foi aplicado, observou-se alteração dessa resposta ao final da pesquisa, quando muitos se conscientizaram de serem portadores desse hábito. Em relação ao ronco, ressalta-se que este não foi um aspecto constante na população estudada.

Ao se considerar os fatores causadores da halitose, podem-se salientar as infecções, doenças periodontais, a má higiene bucal incluindo as próteses removíveis, restaurações e próteses defeituosas (Cos$\left.\mathrm{ta}^{16}, 1987, \mathrm{Abdo}^{17}, 2002\right)$. Dentre estes, a doença periodontal já foi bastante investigada e ainda mostra controvérsias nos resultados das pesquisas. A literatura (Orth et al. ${ }^{18}, 2003$ ) ressalta que a terapia periodontal se mostrou efetiva na diminuição dos valores de Compostos Sulfurados Voláteis, mesmo sem interferir na quantidade de saburra lingual formada. Os autores também observaram que a quantidade desses gases, medidos por meio de cromatografia gasosa, foi significativamente maior em pacientes portadores de doença periodontal, indicando a possibilidade da metil-mercaptana agir como um acelerador para a progressão da doença periodontal. Uma possível explicação para a relação entre a doença periodontal e halitose é que as bactérias que produzem os CSV são predominantemente anaeróbicas gram-negativas, similares às envolvidas com a patogênese da periodontite (Hine ${ }^{5}$, 1957). Assim, o tratamento periodontal não leva a alterações nos níveis de compostos sulfurados voláteis em pacientes com periodontite agressiva. No presente estudo, verificou-se que o conhecimento sobre as causas da halitose relacionadas à doença periodontal era precária, uma vez que os voluntários não apresentaram respostas que sugerissem relação direta entre mau hálito e a gengivite. Além disso, grande número de pessoas afirmou não utilizar o fio dental frequentemente e, ainda assim, se consideravam livres do problema bucal.

Nesse contexto, torna-se importante ressaltar que existe um fator direto desencadeante da halitose, sendo este o mais negligenciado pelos portadores dos sintomas de mau hálito. Tal condição seria a presença da saburra lingual, que se caracteriza por massa esbranquiçada e viscosa que se adere ao dorso da língua, em maior proporção no seu terço posterior, formada por células epiteliais descamadas, bactérias e restos alimentares (Calil et al. ${ }^{3}, 2006$, Leite e Montenegro $\left.{ }^{7}, 2006\right)$. É o principal agente etiológico da halitose e forma-se basicamente quando há diminuição do fluxo salivar, descamação epitelial acima dos limites fisiológicos ou, ainda, em ambos os casos. Existe um estudo mostrando várias formas de promover a diminuição da formação da saburra lingual como, por exemplo, aumentando o fluxo salivar ou diminuindo a descamação de células por meio do tratamento de suas causas (Lima et al. ${ }^{19}$, 2006).

A saburra lingual formada se mantém aderida por três motivos principais, a saber: aumento da concentração de mucina na saliva, células epiteliais descamadas ou a presença de microrganismos anaeróbicos proteolíticos (Peruzzo et al. ${ }^{20}, 2006$ ).

Diante desse fato, nota-se a fundamental importância da remoção da saburra lingual por meio da higienização do dorso da língua como medida preventiva do mau hálito. O tratamento profilático recomenda que o cirurgião-dentista estabeleça uma orientação básica dos princípios de higiene com a correta utilização do fio dental, bem como nas técnicas de escovação (língua e elementos dentários). Havendo ainda uma terapêutica mascaradora, utilizando-se elementos odorificantes (colutórios, aerossóis) que disfarçariam o problema do mau hálito (Crispim e Sampaio $^{15}$, 1999, Mariano et al..21, 1999).

Seja qual for a causa da halitose, a higiene bucal é fundamental para o sucesso do tratamento, além da eliminação de sua respectiva causa. É imperativo que além da escovação e do uso do fio dental promova-se a periódica limpeza da língua após as refeições e ao deitar, evitando o acúmulo bacteriano (Kolbe e Britto', 2004, Navas et al. ${ }^{22}$, 2009). Com o avanço 
das pesquisas sobre halitose, sabe-se hoje que o tratamento primário deve ser baseado no combate à causa que determina a produção de gases voláteis causadores do mau hálito e complementação com higiene adequada.

Existem pesquisas (Conceição et al. ${ }^{23}$, 2005, Cerri e Manti ${ }^{4}$, 2000) mostrando que a melhor opção para remoção da saburra lingual está nos raspadores. O uso da escova dental com a finalidade de limpar a língua é limitado, pois esta é apropriada para soltar a saburra lingual, porém pouco eficiente em removê-la.

Desse modo, os raspadores linguais apresentam maior eficácia nas pesquisas que os comparam com outros métodos de higiene da língua (Cerri e Manti ${ }^{24}$, 2000).

Dentre os motivos indicados para o uso dos raspadores linguais, estão: facilidade de uso, sensação de limpeza maior, não provocar ferimentos, abranger toda a superfície lingual de uma só vez, menor quantidade de movimentos necessários para a higiene e menor estímulo para os reflexos de ânsia. Todavia, há autores que constataram que, na opinião da população, a escova dental é mais utilizada por alguns motivos como: ser mais prática, já que é o mesmo instrumento de higiene usado para os dentes e, embora provoque mais ânsia, consideram sua limpeza mais eficaz que a do raspador (Chaim $\left.{ }^{25}, 2001\right)$.

Entretanto, é nesse ponto que se nota grande ineficiência na prevenção do mau hálito, pois os pacientes geralmente se utilizam de alternativas para eliminar o odor como pastilhas, soluções para bochecho, gomas de mascar e dentifrícios (Abdo ${ }^{17}$, 2002). Neste trabalho, os voluntários relataram, quando questionados sobre o fator de prevenção da halitose, que o método utilizado por eles era, em maior escala, a higienização bucal em si, tendo uma pequena parcela se dividido entre o consumo de gomas de mascar e água.

$\mathrm{O}$ que se pode perceber com esta investigação entre pacientes e o levantamento da literatura pertinente ao assunto é que o mau hálito é incontestavelmente um impedimento ou um fator de incompatibilidade dos contatos pessoais e, muitas vezes, torna-se causa de isolamento social, levando o indivíduo a um afastamento voluntário, no caso de se considerar um portador da halitose, ou discriminatório, quando outras pessoas se afastam do indivíduo que a possui (Crispim e Sampaio ${ }^{15}$, 1999). Em sua maioria, os voluntários entrevistados neste estudo acreditavam não serem portadores de mau hálito, e outros relataram desconhecer serem ou não portadores desse problema, com poucos confessando possuírem esse mal. Isso reforça a crença de que muitas pessoas que pertencem ao grupo de portadores do mau hálito, no entanto, ainda ignoram os sintomas em si próprios (Silveira et al. ${ }^{26}, 2006$ ). Tal acontece, principalmente, pelo fato do olfato se adaptar por tolerância, passando a não registrar mais a presença do odor predominante. Tal fenômeno ocorre após cerca de um minuto sem perder a capacidade de detectar novos odores que surjam no ambiente.

Desse modo, considera-se que o presente estudo deve ser ampliado para que além da avaliação dos conhecimentos sobre halitose, a população também seja investigada quanto aos hábitos alimentares e de higiene, de uma forma mais detalhada, que possam interferir no aumento da produção de compostos sulfurados voláteis pelas bactérias presentes na cavidade bucal, particularmente, na saburra lingual.

\section{CONCLUSÃO}

Frente ao exposto, conclui-se que:

- O conhecimento da população estudada sobre halitose se mostrou controverso em alguns aspectos, principalmente no que diz respeito às causas e formas de prevenção.

- Não foi observada melhora no conhecimento sobre halitose para o grupo que recebeu o folheto, em comparação com o grupo-controle;

- Tanto os profissionais como a população devem ser melhor orientados quanto aos fatores fisiológicos e patológicos da halitose, para que, assim, possam atuar na prevenção de seus efeitos individuais e sociais.
$A B R E U$ AC

DOMINGOS PAS

DANTAS AAR

CAUSAS E

SINTOMAS DA

HALITOSE:

ESTUDO DO

CONHECIMENTO

ENTRE PACIENTES

DO CURSO DE

ODONTOLOGIA
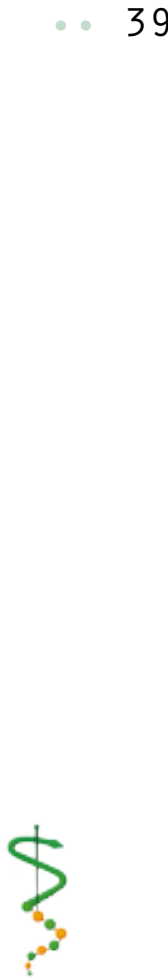

REVISTA DE ODONTOLOGIA DA UNIVERSI DADE CIDADE DE SÃO PAULO

2011; 23(1): $30-$

41 , JAN-ABR 
ABREU AC

DOMINGOS PAS

DANTAS AAR

CAUSAS E

SINTOMAS DA

HALITOSE:

ESTUDO DO

CONHECIMENTO

ENTRE PACIENTES

DO CURSO DE

ODONTOLOGIA

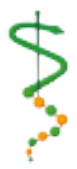

REVISTA DE ODONTOLOGIA DA UNIVERSIDADE CIDADE DE SÃO PAULO 2011; 23(1): 30 41 , JAN-ABR
REFERÊNCIAS

1. Kolbe AC, Britto PK. Halitose: principais origens, incidência e efeitos colaterais na geriatria. Rev Inter Estomatol 2004 abr./jun.;1(1):40-4.

2. Fernandes LA, Lima DCd, Gulinelli JL, Bidóia ÉM, Garcia VG. Halitose: aspectos de importância clínica para o cirurgião-dentista Rev Fac Odontol Lins 2007 jan./ jun.;19(1):57-63.

3. Calil C, Tarzia O, Marcondes F. Qual a origem do mau hálito? Rev Odontol UNESP 2006 35(3):185-90.

4. Gorender ME. Correlação entre halitose e esquiva social. Rev Bras Neurol Psiquiatr 2004 8(2):68.

5. Hine MK. Halitosis. J Am Dent Assoc 1957 Jul;55(1):37-46.

6. Moreno T, Haas AN, Castro GD, Winter R, Oppermann RV, Rõsing CK. Tratamento da periodontite agressiva e alterações nos compostos sulfurados voláteis. Rev odonto ciênc 2005 jul.-set.;20(49):217-21.

7. Leite J, Montenegro F. A importância do uso dos limpadores linguais nos pacientes idosos. 2006. Disponível em: http://www.odontologia.com.br/artigos.asp?id=602.

8. Derceli JdR, Tardivo TA, Pires JR, Massucato EMS, Orrico SRP, Spolidorio DMP. Estudo comparativo da microbiota bucal após a utilização de limpadores linguais. Rev odontol UNESP 2005 34(3):93-7.

9. Montenegro F, Marchini L, Leite J, Manetta C. Tipificando e classificando os limpadores linguais disponíveis no mercado brasileiro. Rev EAP/APCD 2006 dez.;8(1):125 .

10. Albuquerque JAP, Santos AAd, Gonçalves SRJ, Bomfim AMA, Calado AA, Santos JAd. A importância do cirurgião-dentista na prevenção, diagnóstico e tratamento da halitose Odontol clín-cient 2004 set.-dez.;3(3):169-72.

11. Koshimune S, Awano S, Gohara K, Kurihara E, Ansai T, Takehara T. Low salivary flow and volatile sulfur compounds in mouth air. Oral Surg Oral Med Oral Pathol Oral Radiol Endod 2003 Jul;96(1):38-41.

12. Cerri A, Silva CEXSR. Avaliaçäo de métodos mecânicos no controle da halitose relacionada à língua saburrosa $J B C$ j bras clin odontol integr 2002 jul.-ago.;6(34):312-6.

13. Carvalho M, Toledo S, Benatti B, Tabchoury C, Filho GN. Eficácia de 4 colutórios brasileiros na redução do mau hálito matinal. Period 2003 13: 10-4.

14. Faber J. Halitose. Revista Dental Press de Ortodontia e Ortopedia Facial 2009 14: 14-5.

15. Crispim ASS, Sampaio MCC. Halitose: um desafio para o estomatologista Rev Fac Odontol Univ Fed Bahia 1999 jan.-jun.;18: 53-9.

16. Costa I. Patogenia das halitoses. Odontol Mod 1987 14(6):7-16.

17. Abdo EN. Halitose: uma questão angustiante Rev $A B O$ nac 2002 jun.jul.;10(3):179-82.

18. Orth CC, Siqueira FS, Reichert MR, Leitune VCB, Haas AN, Rõsing CK. Compostos sulfurados voláteis, placa dental gengivite em estudantes de odontologia da Universidade Estadual do Rio Grande do Sul Rev Fac Odontol Porto Alegre 2003 dez. ;44(2):26-30.

19. Lima LL, Peruzzo DC, Ribeiro EDP, Bittencourt S, Nogueira-Filho GdR, Júnior FHN, et al. Avaliação do efeito da terapia periodontal não cirúrgica na formação de compostos sulfurados voláteis (csv). Periodontia 2006 dez.;16(4):52-7. 
20. Peruzzo DC, Filho WLSeS, Salvador SL, Sallum AW, Nogueira-Filho GdR. Correlação entre as medidas de compostos sulfurados voláteis (Csv) no hálito matinal e o teste bana de saburra lingual Periodontia 2006 jun;16(2):14-9.

21. Mariano R, Vicentin C, Kolbe A, Mariano L. Avaliação quantitativa da capacidade de remoção dos resíduos do dorso da língua através do uso de dois limpadores na contribuição para a redução da halitose. J Assoc Odontol 1999 3(16):13-21.

22. Navas EAFdA, Inocêncio AdC, Jorge AOC, Koga-Ito CY. Avaliação da utilização de limpador de língua na redução dos níveis de leveduras na cavidade bucal. Rev Odontol UNESP 2009 38(2):99-103.

23. Conceição MDd, Marocchio LS, Fagundes RL. Uma nova técnica de limpeza da língua Rev Assoc Paul Cir Dent 2005 nov.-dez.;56(6):465-9.

24. Cerri A, Manti D. Halitose: esse problema tem tratamento? Rev Bras Cir Cabeça Pescoço 2000 2: 74-6.

25. Chaim LAdF. Comparaçäo entre o uso de um raspador de língua simplificado (RLS) e uma escova dental na higiene da língua $\operatorname{Rev} A B O$ nac 2001 ago.-set.;9(4):242-6.

26. Silveira EMV, Gomes SC, Oppermann RV, Rõsing CK. Estudo das correlações entre diferentes recursos diagnósticos do hálito em pacientes portadores de periodontite crônica sob tratamento da gengivite Periodontia 2006 jun.;16(2):83-8.

Recebido em: 16/02/2011

Aceito em: 28/03/2011

ABREU AC

DOMINGOS PAS

DANTAS AAR

CAUSAS E

SINTOMAS DA

HALITOSE:

ESTUDO DO

CONHECIMENTO

entre pacientes

DO CURSO DE

ODONTOLOGIA

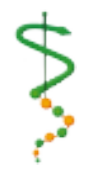

REVISTA DE

ODONTOLOGIA DA

UN I VERS I DADE

CIDADE DE SÃO

PAULO

2011; 23(1): 30 -

41, JAN-ABR 